\title{
IETS OVER DE MALARIA IN SURINAME
}

\section{DOOR}

\author{
DR. E. VAN DER KUYP ${ }^{1}$ )
}

Inleiding

De malaria is door alle eeuwen heen een ware gesel der mensheid geweest. Geschriften uit de Bijbel en van de oude Grieken en Romeinen doen veronderstellen, dat vele streken reeds vóór Christus door de malaria geteisterd werden. Thans wordt ze nog, gelet op haar verbreiding en de door haar veroorzaakte sterfte, als een van de voornaamste ziekten beschouwd. Dit blijkt wel uit het volgende.

Volgens een rapport van 1932 van de Volkenbond werden in één jaar tijds bijna 18 millioen gevallen van malaria in 65 landen behandeld. Dit cijfer is als werkelijke index van het heersen van de malaria erg laag te noemen, wanneer men bedenkt, dat slechts een gedeelte van de patienten zich onder medische behandeling stelt. In Brits-Indië bv. schat de Malaria Commissie het aantal gevallen van malaria op 100 millioen, terwijl slechts 8-10 millioen gevallen worden behandeld. Meer dan 3 millioen mensen sterven daar jaarlijks aan koorts. Tijdens een malaria-epidemie in Ceylon in 1934-1935 stierven er 66.704 personen. In 1935 werden $61 / 2$ van de 61 millioen inwoners van verscheidene Britse koloniën wegens malaria behandeld, of wel $25 \%$ van alle ziektegevallen.

De malaria bleek vaak machtiger dan de grootste veldheren te zijn. De legers van Julius Caesar en Napoleon bv. hadden er ernstig van te lijden. Van 1916-'18 werden 162.000 opnemingen in de hospitalen bij 124.000 Britse manschappen wegens malaria geboekt (velen werden herhaaldelijk opgenomen). Daarom begrepen de Amerikanen, dat ze in de tweede wereldoorlog niet alleen tegen de asmogendheden hadden te vechten, maar tevens tegen de malariamuskiet. De soldaten kregen niet alleen een opleiding in het hanteren van wapens, e.d., maar ook in het gebruik van anti-malaria middelen. Het Amerikaanse leger was dan ook goed toegerust met deze middelen en telde meer dan 250 entomologen.

En toch werden tijdens de actie op Sicilië meer Amerikaanse en Britse soldaten door de malaria dan door het wapengeweld van de vijand buiten gevecht gesteld.

1) Uit het Instituut voor Tropische Hygiëne, Amsterdam. 
De schade, door de malaria veroorzaakt, is zeer ernstig en komt op verschillende wijzen tot uiting:

1. Verlies aan geld door derving van inkomsten, door doktersen apothekersrekeningen, zowel voor het individu, de onderneming, als het land.

2. Verlies aan tijd door de vele ziektedagen en de verminderde arbeidsprestatie. De vruchtbaarste landstreken worden juist het meest door de malaria geteisterd.

3. Malaria ondermijnt zowel het lichaam als de geest. Vooral op de ontwikkeling van het kind heeft ze grote invloed.

4. De sterfte onder malarialijders is groot, niet alleen aan de aandoening zelf, maar ook aan bijkomstige ziekten, waaraan het verzwakte lichaam gemakkelijk ten prooi valt.

Alhoewel de gematigde luchtstreken niet geheel vrij zijn van malaria, vormt ze er toch geen groot probleem. Het mensdom in de tropen en subtropen echter, gaat zwaar gebukt onder deze ellendige last, die de gezondheidsdiensten grote zorgen baart en de ontwikkeling van de betreffende landen zeer tegenhoudt.

De malaria is gekenmerkt door het optreden van koortsaanvallen, die 6-16 uren duren en zich rhythmisch herhalen. Daartussen zijn telkens koortsvrije perioden. De aanvallen beginnen met koude rillingen en eindigen met zweten. Van de vele andere verschijnselen is de vergroting van de milt belangrijk voor het bevolkingsonderzoek.

Kwaadaardige vormen kunnen gepaard gaan met bewusteloosheid, stuipen, verlammingen, heftige diarrheeën, tijdelijke krankzinnigheid, w.o. ernstige opwinding (amok) enz.

Malaria heeft bij ondoelmatige behandeling de neiging, chronisch te verlopen en vaak te recidiveren, het lichaam daarbij steeds meer en meer ondermijnend.

De verwekkers van de malaria zijn Plasmodium-soorten, intracellulaire parasieten die de rode bloedlichaampjes vernielen. De voornaamste drie zijn: Plasmodium falciparum, de verwekker van de malaria tropica, $P$. vivax, verwekker van de malaria tertiana en P.malariae, verwekker van de malaria quartana.

De tropica komt het meest in de tropen voor. Het verloop is heftig en de sterfte groot. De patient lijdt dagelijks of om de dag aan koorts.

De tertiana komt niet alleen in de tropen, maar ook in de gematigde luchtstreken voor, waar ze over het algemeen de enig heersende vorm is. Het verloop is minder heftig, maar gekenmerkt door de vele recidieven. De patient heeft om de dag koorts. 
De quartana is zeldzamer. Het verloop is goedaardig, maar meestal chronisch. Om de twee dagen treedt de koorts op. Juist door het milde verloop wordt deze aandoening het meest veronachtzaamd en kan daardoor niercomplicaties veroorzaken.

De malariaverwekkers worden van de ene op de andere persoon overgebracht door uitsluitend vrouwelijke malariamuskieten, Anopheles-soorten. Thans zijn hiervan al meer dan 250 verschillende bekend. Gelukkig zijn niet alle gevaarlijk. Tegenwoordig is de meest gevreesde Amerikaanse malariamuskiet de Anopheles darlingi. Een nog gevaarlijker soort is de Afrikaanse Anopheles. gambiae, die omstreeks 1930 van Dakar, waarschijnlijk per schip of vliegtuig, naar Natal in Brazilië werd overgeplant. Deze muskiet verspreidde zich snel en veroorzaakte heftige malariaepidemieën. Van 1938-'39 alleen had ze ongeveer 14.000 doden op haar geweten. Het spreekt vanzelf, dat met man en macht getracht werd haar uit te roeien. En Goddank gelukte dit de Braziliaanse regering, daarbij geholpen door de Rockefeller Foundation. Anders waren de gevolgen voor de Nieuwe Wereld niet te overzien geweest.

Anophelinen tonen onderling niet alleen morphologische, maar ook biologische verschillen. Zo stelt elke soort of elke groep weer aparte eisen aan de broedplaatsen. Vandaar dat sommige waterplassen geheel ongeschikt zijn voor bepaalde gevaarlijke soorten. Wie dus zomaar met de uitroeiïng van de Anophelinen wil beginnen, zal tonnen gouds verkwisten. Een grondig entomologisch onderzoek ter plaatse moet voorafgaan, om te bepalen, welke soort of soorten gevaarlijk zijn en om de biologische eigenschappen ervan te leren kennen. Dan pas kan men deze soort(en) aanvallen (species assainering volgens SwELlengrebel). De leek moet echter niet denken dat dit probleem zo gemakkelijk is, want soms maakt men door de getroffen maatregelen de levensvoorwaarden voor een beruchte Anopheles onmogelijk, maar voor een andere, nog gevaarlijker soort juist geschikt.

Uitroeiïng van een muskiet kost ontzettend veel geld. Beperking van het aantal kost veel minder, maar moet zonder onderbreking voortgezet worden. Het is soms echter niet gemakkelijk, degenen, die de nodige fondsen ter beschikking moeten stellen, daarvan te overtuigen.

In het bloed van de malariapatient kunnen zich geslachtelijke en ongeslachtelijke vormen van de malariaparasiet bevinden. Alleen wanneer de muskiet bloed zuigt, waarin mannelijke en vrouwelijke geslachtsvormen vóórkomen, wordt ze geinfecteerd. 
De parasiet ondergaat een zekere ontwikkeling in de Anopheles, die in de tropen 9-12 dagen duurt, waarna de muskiet in staat is een mens te infecteren. Maandenlang blijft ze als zodanig gevaarlijk.

De verbreiding van de malaria onder een bevolking kan men nagaan, door de bewoners te ondervragen, officiële medische rapporten van het gebied te bestuderen, de milt van de mensen te betasten om het percentage personen met een vergrote milt (milt-index) te bepalen, het bloed van de mensen te onderzoeken enz. Door dit laatste komt men het percentage dergenen met een positief bloedpreparaat (parasietenindex) te weten, de soort parasieten die er voorkomen, hun dichtheid, de index van de geslachtelijke vormen (voor de overbrenging van belang), enz.

De malaria in Suriname

Alhoewel op Curaçao Anopheles pseudopunctipennis pseudopunctipennis voorkomt, is er, dank zij haar geringe dichtheid, nog nooit een autochthoon geval van malaria gerapporteerd. Gunstige factoren hiervoor zijn o.a.: de geringe grootte van Curaçao, het geisoleerd zijn van het eiland in de Caraïbische zee, de zeer geringe regenval en de rotsige bodem, die niet genoeg geschikte broedplaatsen biedt. Ook van de andere Nederlandse Antillen is nog nooit een inheems geval van malaria medegedeeld.

Van Suriname daarentegen zou men kunnen zeggen, dat de

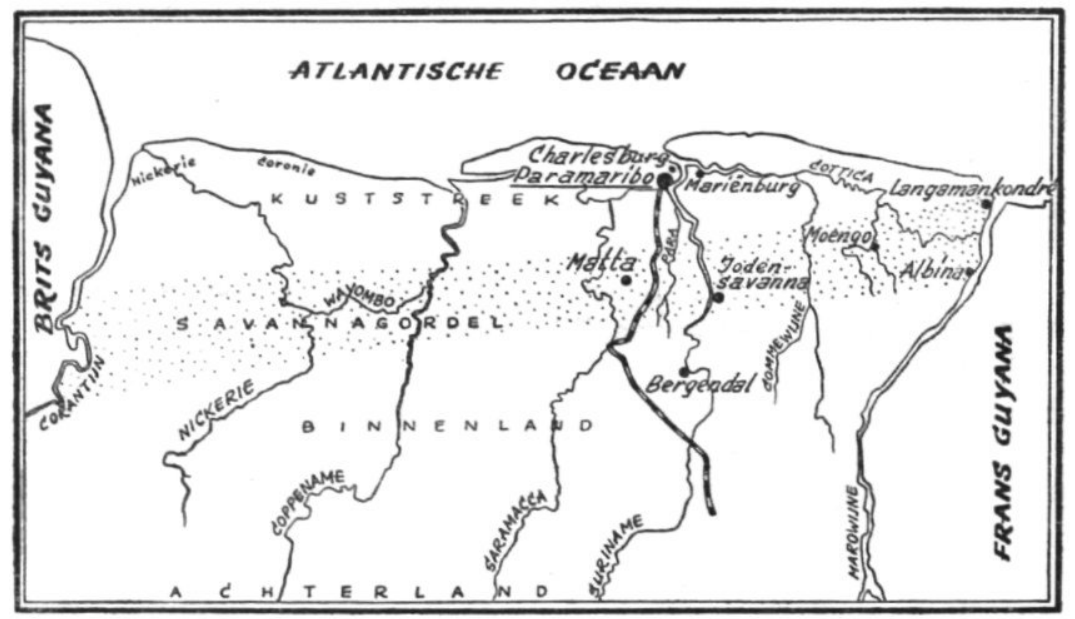

Fig. 1. Schetskaartje van het Noordelijk deel van Suriname, met in de tekst genoemde namen van plaatsen, rivieren en streken. De savannagordel is gestippeld. 
malaria een van de voornaamste ziekten is, waarmede vooral emigranten danig rekening moeten houden.

Om de verbreiding van de malaria goed te kunnen begrijpen, moet men zich Suriname in vier gebieden verdeeld denken (zie fig. 1); van het Noorden naar het Zuiden toe:

1. de moerassige, alluviale kuststreek,

2. de kale, zandige savannagordel (op het kaartje gestippeld),

3. het bos- of binnenland en

4. het achterland, waarvan nog heel weinig bekend is.

Reeds lang is het binnenland berucht als de meest ernstige malaria-haard van het land. Dit blijkt duidelijk uit de geschiedenis van Suriname.

Bergendal is een voorbeeld van zo'n berucht malaria-oord. Hier vestigden zich o.a. Moravische broeders in 1736 en Duitsers in $1744,1747,1897$ en 1935. Velen stierven er aan de koorts en de rest vertrok telkens spoedig weer.

Ook de geschiedenis van de gevechten tegen de naar het binnenland gevluchte slaven is welbekend. De Europeanen waren verplicht vrede te sluiten, omdat ze niet in staat waren de strijd tegen hun bitterste vijand, de malaria, aan te binden.

Menig goud-, hout- en balatabedrijf heeft zijn ondergang aan de malaria te wijten, want ook zijn arbeiders ontkomen niet aan de infectie en haar gevolgen.

De eerste nauwkeurige gegevens over de malaria in het binnenland zijn verzameld bij de aanleg van de spoorweg in het begin van deze eeuw.

Zolang nog ten Noorden van kilometer 67 gewerkt werd, ging het goed. Het ziektecijfer was zeer gering en er kwam practisch geen malaria voor. Nauwelijks echter was het werk voorbij deze plek gevorderd, of de ellende begon.

Bij een 400 Aziaten moest $30 \%$ verzuim wegens malaria en daarenboven $20 \%$ evacuatie (wegens ziekte?) geboekt worden.

Ruim 400 arbeiders uit Curaçao werden in het begin van 1905 aan het werk gesteld. Binnen een maand had $20 \%$ malaria en later zelfs $50 \%$. Toen een 15 -tal stierven, begon de repatriëring, die in September 1905 voltooid was.

71 Indonesiërs, aangeworven op Java, werden dan eens bij de spoorwegaanleg, dan weer in het kustgebied te werk gesteld. Toch leden ze zodanig aan de malaria, dat ze vóór de afloop van hun werkcontract het land moesten verlaten.

Een 200 tal Negers uit Barbados werd in 1906 in dienst geno- 
men. Binnen een jaar moesten ook zij terug vanwege de malaria.

De verliezen aan mensenlevens en geld waren zo groot, dat het werk werd voortgezet met een beperkt personeel, bestaande uit Negers van de Guyana's, die bestand bleken te zijn tegen de malaria. Alhoewel het werk daarna slechts langzaam opschoot, bleek dit toch een besparing te zijn, want met een groter aantal, doch zwaar zieke arbeiders waren de bijzondere kosten onevenredig groot vergeleken met het geringe arbeidsverzet.

De vrijwel enige permanente bewoners van het binnenland zijn de z.g. Bosnegers, afstammelingen van de vroeger van de plantages weggelopen Afrikaanse slaven. Hun kinderen zijn zeer ernstig geinfecteerd met malariaparasieten en wel hoofdzakelijk met Plasmodium falciparum. Nagenoeg alle zuigelingen lijden al aan malaria. Maar hoe ouder de mensen worden, hoe meer tolerantie ze tonen voor de parasieten. De volwassenen bv. hebben nog wel parasieten in hun bloed, maar deze bezorgen hun weinig last: er is een symbiose ontstaan tussen mens en parasiet. Hierdoor is de persoon ongevoelig voor nieuwe infecties door dezelfde soort parasiet.

Alhoewel een groot percentage van de schoolkinderen op de boslandscholen temperatuursverhoging toont, schijnen ze de ziekte tamelijk goed te kunnen verdragen. Immers, zij spelen en hun sterfte is klein voor een natuurvolk. Doch hierin schuilt het grootste gevaar voor de bezoeker. De inheemse bevolking schijnt gezond te zijn. De bezoeker acht de waarschuwingen over het „moorddadige binnenland" erg overdreven en treft niet of onvoldoende de maatregelen, die hem aanbevolen zijn, met het welbekende gevolg, waaraan niet alleen het binnenland, maar ook geheel Suriname zijn kwade roep over zijn gezondheidstoestand te danken heeft.

Niet alleen de onbevaarbare rivieren, maar ook de malaria tropica maakt de exploitatie van het binnenland voorlopig onmogelijk.

In de savannagordel is de malaria-verbreiding ietwat anders dan in het binnenland. De voornaamste bewoners zijn hier de Indianen. In de buurt van Moengo vindt men echter hoofdzakelijk Bosnegers en in de Paradorpen voornamelijk Creolen.

Uit tabel 1 kan men afleiden, dat de Paradorpen voor de tropen zeer lage cijfers tonen. Daarentegen zijn vele andere dorpen er heel erg aan toe. Ook blijkt, dat de volwassen Indianen geen tolerantie voor de malariaparasieten ontwikkelen zoals de Bosnegers. Terwijl bij de Bosnegers van de meest ernstig geinfecteerde oorden in $193915,5 \%$ van de kinderen en slechts 3,2\% 
TABEL 1. Miltindices in het savannagebied omstreeks 1911 (FLU), in 1938 (VAN DER KUYP) en 1939 (SWELlENGREBEL \& VAN DER KUYP).

\begin{tabular}{|c|c|c|c|c|c|c|}
\hline \multirow[b]{2}{*}{ Jaar } & \multirow[b]{2}{*}{ Plaats } & \multirow[b]{2}{*}{ Ras } & \multicolumn{2}{|c|}{ Kinderen } & \multicolumn{2}{|c|}{ Volwassenen } \\
\hline & & & $\begin{array}{l}\text { Onder- } \\
\text { zocht }\end{array}$ & $\begin{array}{c}\text { Miltin- } \\
\operatorname{dex}\end{array}$ & $\begin{array}{c}\text { Onder- } \\
\text { zocht }\end{array}$ & $\begin{array}{l}\text { Miltin- } \\
\text { dex }\end{array}$ \\
\hline 1939 & Langamankondré . . . . . & Indianen & 40 & 100 & 15 & 100 \\
\hline, & Albina . . . . . . . . & & 58 & 67,2 & & \\
\hline , & 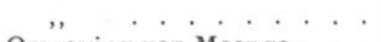 & Creolen & 18 & 66,7 & & \\
\hline , & Omgeving van Moengo . . . & Bosnegers & 211 & 4,3 & 145 & 5,5 \\
\hline ," & $\begin{array}{lllll} & , & , & \end{array}$ & Indonesiërs & 70 & 21,4 & 56 & 7,1 \\
\hline , & Boven-Commewijne . . . . & Indianen & 28 & 78,6 & 28 & 53,6 \\
\hline , & Omgeving van Jodensavanna & & 111 & 9,9 & 60 & 18,3 \\
\hline & $,, \quad, \quad$, & Creolen & 41 & 9,8 & 44 & 20,5 \\
\hline \pm 1911 & Paradorpen. . . . . . . & , & 227 & 1,8 & & \\
\hline 1939 & , $\quad . . . . . .$. & & 356 & 6,7 & 115 & 6,1 \\
\hline \pm 1911 & Matta . . . . . . & Indianen & 16 & 37,5 & 32 & 59,4 \\
\hline 1939 & 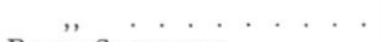 & , & 106 & 10,4 & 61 & 24,6 \\
\hline \pm 1911 & Boven-Saramacca . . . . . &, & 36 & 44,4 & & \\
\hline 1938 & Boven-Coppename $+\mathrm{Wa}-$ & & & & & \\
\hline 1939 & $\begin{array}{c}\text { yombo } \\
\text { Boven-Coppename }+ \text { Wa- }\end{array}$ & ,", & 93 & 58,1 & & \\
\hline & yombo. . . . . . & ", & 137 & $79 ; 6$ & 89 & 76,4 \\
\hline
\end{tabular}

van de volwassenen, die zich bij de medicus aanmeldden, klaagden over koorts, bedroeg dit percentage bij heel erg geinfecteerde Indianen 26,0 bij kinderen en 35,4 bij volwassenen (SwELleNGREBEL \& VAN DER KUYP). De Indianen zijn evenals de Bosnegers voornamelijk met $P$. falciparum geinfecteerd, doch hun sterfte is veel hoger dan van de Bosnegers.

Terwijl de Bosnegers als reservoirs dienen voor de tropicaparasiet, verspreiden de Indianen door hun nomadische leefwijze deze parasiet over het savannagebied, aldus een zeker contact onderhoudend tussen de malaria van het binnenland en die van de kust. Ze wonen nl. dan eens in de buurt van de Bosnegers, dan weer dichtbij de kuststreek.

De kust toont weer een geheel ander beeld. Ten eerste komt de malaria vnl. in goedaardiger vormen voor. Op sommige plaatsen nl. overweegt de malaria tertiana, op andere de quartana, alhoewel de tropica niet geheel ontbreekt. Immers in de kuststreek was, omstreeks 1911, 12,7\% van alle infecties te wijten aan $P$. falciparum (FLU) en in 1939 14\% (SWELLENGREBEL \& VAN DER KUYP). Ten tweede bereiken zelfs de ergst geinfecteerde streken niet zulke hoge indices als het binnenland en het savannagebied (Langamankondré ligt wel aan de kust, maar moet tot 
de savannagordel, die schuin over het land loopt en de kust in het uiterste Oosten bereikt (zie fig. 1), gerekend worden). Ten derde is de verbreiding der malaria in deze streek zeer grillig. Paramaribo, waar meer dan een derde gedeelte van de bevolking van het gehele land woont, is practisch vrij van malaria, uitgezonderd de buitenwijken. Het is nooit bewezen, dat de gevallen van tropica, die zo heel zelden in het centrum van Paramaribo worden gevonden, inderdaad autochthoon zijn. De districten Nickerie en Coronie zijn ook nagenoeg vrij van malaria. Daarentegen zijn de plantages en vestigingen aan de beide oevers van de benedenloop van de Suriname en Commewijne vrij ernstig geinfecteerd. Hier en daar aan de Saramacca, Commewijne en

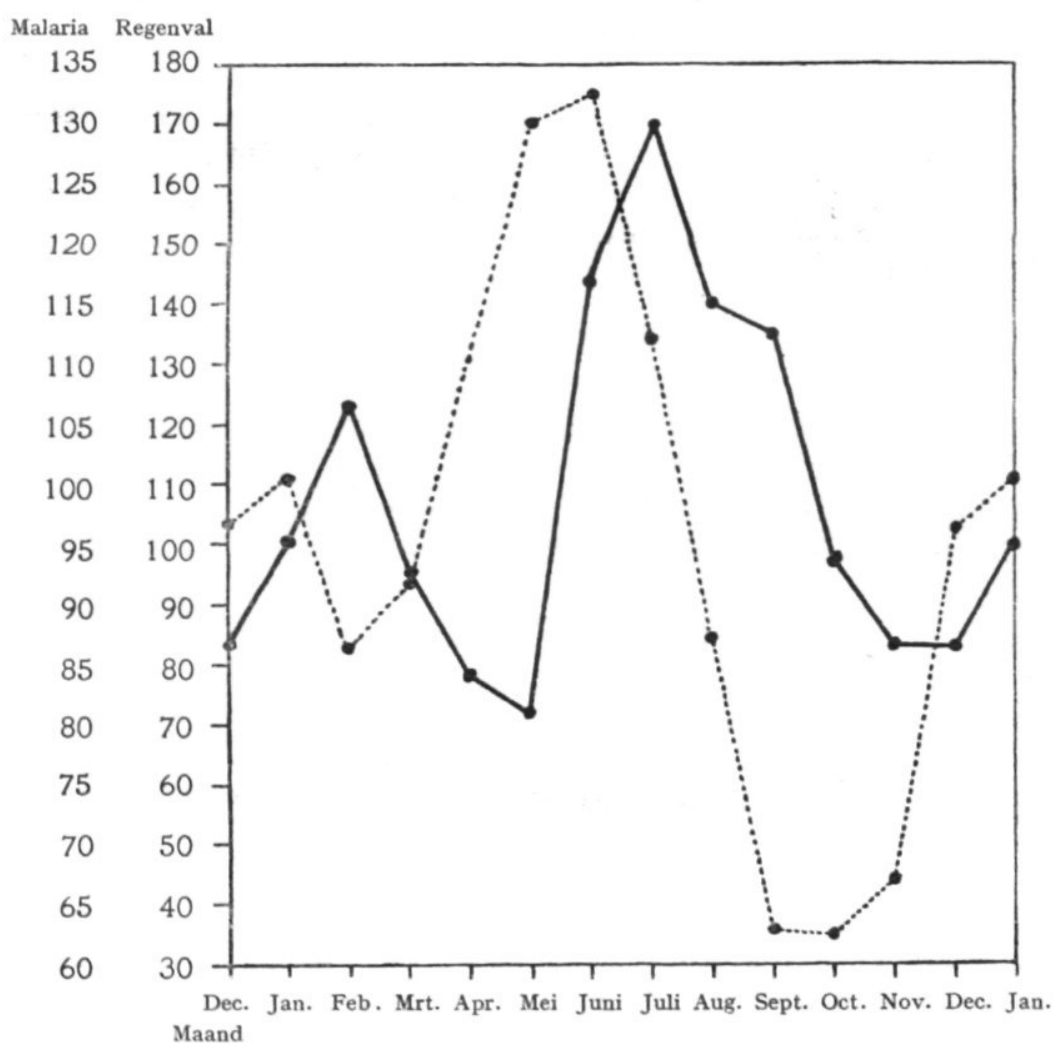

Fig. 2. Grafische voorstelling van het verband tussen mala ria en regenval in Suriname; seizoen-periodiciteit, 1930-1948. - De getrokken lijn geeft het percentage van het gemiddelde aantal gevallen van malaria per maand aan; de gestippelde het percentage van de gemiddelde maandelijkse regenval in $\mathrm{mm}$. 
Cottica en ten Zuiden en Westen van Paramaribo is de toestand vrij gunstig.

Helaas blijft de situatie niet altijd even gunstig, althans in sommige gebieden. Zo zijn heftige malaria epidemieën vastgesteld in Coronie in 1891 en in Nickerie in 1891-'96, 1911-'12, 1918-'19 en 1926-士'29. Ook in het savannagebied, bv. in Matta (FLU), Moengo (BonNe), in Langamankondré (A. E. WolfF) en in de Paradorpen ( $\mathrm{F}_{\mathrm{LU}}$ ) zijn dergelijke epidemieën waargenomen. En zo wisselt het aantal gevallen van malaria, gerapporteerd door de districts-geneesheren, van jaar tot jaar.

Behalve deze jaarlijkse periodiciteit bestaat er ook een seizoen periodiciteit (zie fig. 2). De malariacurve loopt ongeveer parallel aan de regencurve, maar blijft daarbij ongeveer twee maanden ten achter, hetgeen heel logisch is, wanneer men in aanmerking neemt de tijdsduur voor de vorming van lang genoeg bestaande, geschikte broedplaatsen, de duur van het broeden van de muskieten, de gemiddelde periode vóór de Anopheles zich aan een geschikte malariapatient heeft geinfecteerd, de ontwikkelingsduur van de parasiet in de muskiet en de incubatietijd bij de mens.

Dat in Suriname de malaria een zeer voorname rol speelt, blijkt ook wel uit de volgende cijfers over het tijdvak 1931-1947, herleid uit de gegevens van de maand- en jaarrapporten van het Gouvernement.

Per 1000 districtsbewoners werden jaarlijks gemiddeld 68 gevallen van malaria aangegeven; $10,7 \%$ van alle door de districtsgeneesheren gerapporteerde ziektegevallen was te wijten aan malaria. Per 100.000 districtsbewoners stierven jaarlijks gemiddeld 44 aan malaria; $3,6 \%$ van de met name genoemde sterfgevallen in Suriname was te wijten aan malaria.

Ook de ziekenhuiscijfers spreken voor zichzelf. Van 1920 t/m 1940 was $5,0 \%$ van de bijna 60.000 patienten van 's Lands Hospitaal te Paramaribo (vroeger Militair Hospitaal geheten) lijdende aan malaria. In dit centraal ziekenhuis worden patienten van het gehele land opgenomen. Op 13,0\% van de ruim 8.000 ziektegeschiedenissen van patienten, behandeld in het ziekenhuis van de suikeronderneming Mariënburg van 1933 t/m 1939, werd malaria als hoofd- of bijkomstige diagnose vermeld.

De malariamuskieten in Suriname

In de loop der tijden zijn in totaal 16 verschillende Anophelinen in Suriname gevonden en wel voor een groot gedeelte door BoNNE $\&$ BONNE-WEPSTER. 
Voor het gemak kan men ze in twee categorieën verdelen: de Nyssorhynchus-groep en de non-Nyssorhynchus soorten. Van de laatste is geen van de 10 soorten van enige betekenis voor de malaria-overbrenging. De Nyssorhynchus-groep bestaat in Suriname uit 6 of meer soorten, waarvan slechts twee belangrijk zijn: de zeer gevaarlijke Anopheles darlingi en de minder gevaarlijke Anopheles aquasalis.

Probeert men een correlatie tussen de verbreiding van de malaria en de Anopheles-soorten te vinden, dan gelukt dit ten dele. Waar heel veel malaria voorkomt, vindt men de darlingi en waar de darlingi huist wordt heel veel malaria gevonden. Vandaar de associatie van deze twee in het binnenland en in de ernstige haarden in het savannagebied. Aan de kust echter is ze nooit aangetoond. Wel wordt als oorzaak van de malaria epidemieën in de kuststreek een invasie van de darlingi verondersteld (SwELLENGREBEL \& VAN DER KUYP).

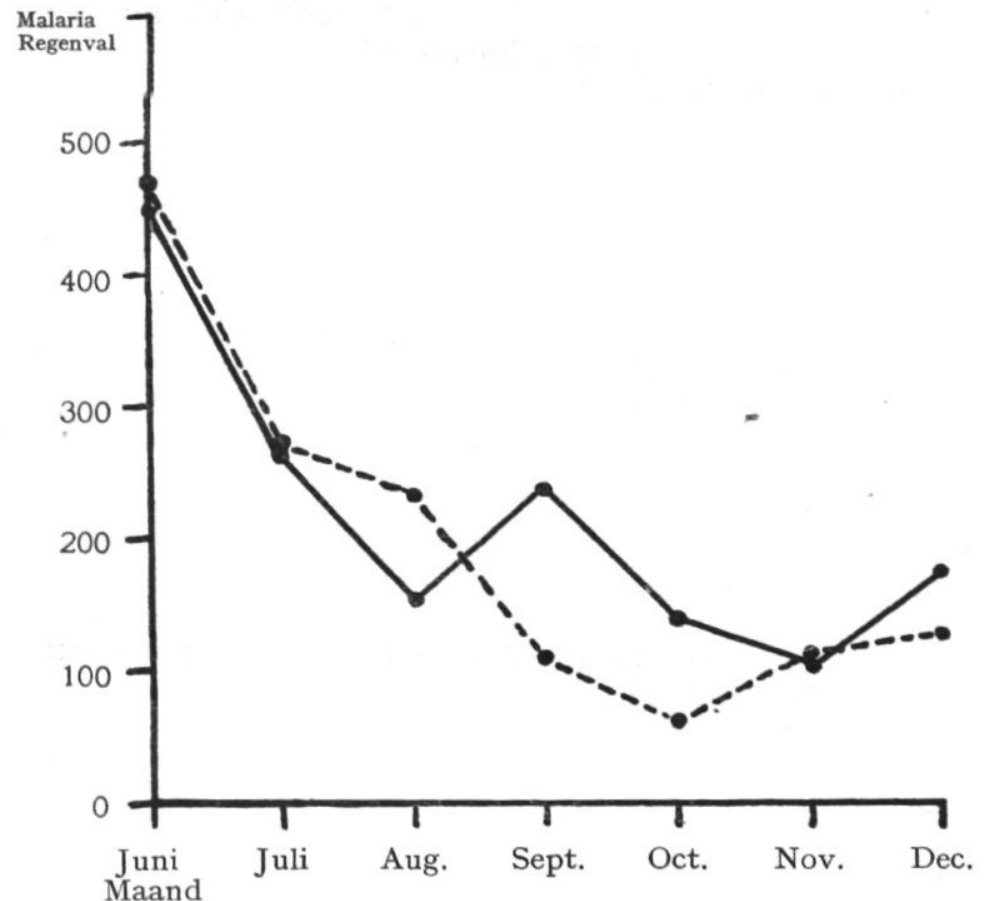

Fig. 3. Grafische voorstelling van het verband tussen de regenval en het aantal verzamelde muggen, behorende tot de Nyssorhynchusgroep, in Charlesburg, 1940. - De getrokken lijn geeft het aantal muggen aan; de gestippelde de regenval in mm. (Fig. 2 en 3 uit de Contribution to the study of the malarial epidemiology in Surinam, 1950). 
Doch de oorzaak van de grillige verbreiding der malaria aan de kust blijft voorlopig onopgelost. In vele Amerikaanse landen speelt de aquasalis een rol bij de malaria-overbrenging, in andere is ze ongevaarlijk. In Suriname komt deze Anopheles overal in het kustgebied, behalve in Paramaribo, in groten getale voor, niet alleen op plaatsen met veel malaria, maar ook op die met weinig of geen malaria (Coronie en Nickerie). De enige verklaring voor dit feit is, dat men te doen heeft met verschillende soorten van aquasalis, dus met een aquasalis-complex. Hetzelfde was het geval met de Europese Anopheles maculipennis. Pas toen ontdekt was, dat ze uit verscheidene „rassen” bestond, kon men de verbreiding van de malaria in Nederland verklaren. Onderzoekingen op Trinidad wijzen er al op, dat ook spoedig een oplossing voor het aquasalis-probleem kan verwacht worden.

De seizoenperiodiciteit van de malaria wordt gemakkelijk verklaard door de correlatie tussen regenval en aantal Nyssorhynchus-soorten (zie fig. 3).

Tenslotte zij nog opgemerkt, dat het allergrootste gedeelte van de bevolking van het land het kustgebied bewoont. Wanneer men Suriname vergelijkt met Brits en Frans Guyana, waar in de kuststreken al de darlingi en veel malaria voorkomen, dan maakt Suriname, voor wat het malaria-vraagstuk betreft, geen slecht figuur.

Samenvatting

In het voorgaande is eerst het een en ander over de betekenis van de malaria en malariamuskieten in het algemeen aangehaald. Daarna is de malaria-verbreiding in Suriname beschreven.

Het binnenland is de meest beruchte malaria-haard van Suriname, hetgeen te wijten is aan de aanwezigheid van 1. de Anopheles darlingi, de meest gevreesde Amerikaanse malariamuskiet en 2, de Bosnegers, die zelf een tolerantie voor de tropica parasiet ontwikkelen, maar gevaarlijke infectiebronnen voor anderen vormen.

In de savannagordel is de toestand ietwat anders. Er zijn delen, die even erg als het binnenland geinfecteerd zijn, terwijl andere weinig malaria tonen. De hoofdbewoners, de Indianen, ontwikkelen geen tolerantie voor de tropica parasiet, die ook hier de scepter zwaait. Waar de Indianen in zeer hoge mate geinfecteerd zijn, wordt de darlingi aangetroffen.

De kuststreek, waar het allergrootste gedeelte van de bevolking woont, toont een geheel ander beeld. Niet alleen komt de malaria er vnl. in goedaardiger vormen (tertiana en quartana) voor, maar ook in veel mindere mate. Bovendien is haar verbreiding hier zeer grillig. Er zijn bv. districten (Coronie en Nickerie), die nagenoeg vrij van malaria zijn. Doch overal, behalve in de hoofdstad Paramaribo is de Anopheles aquasalis, die voor de overbrenging van de kustmalaria verantwoordelijk moet worden gesteld, in groten getale aanwezig. De enige ver- 
klaring hiervoor is, dat de aquasalis uit een complex van Anophelinen moet bestaan, waarvan slechts een gedeelte gevaarlijk is.

\section{S U M M A R Y}

ON MALARIA IN SURINAM

First the importance of malaria and Anophelines in general has been discussed in the preceding pages. Then the malarial epidemiology in Surinam has been described very briefly.

The interior is the most dangerous malarious region in Surinam because of the presence of 1. Anopheles darlingi, the most efficient American malaria mosquito and 2. the Bush Negroes who, while showing a tolerance to Plasmodium falciparum, preserve this parasite and therefore seriously endanger other people.

In the savannah belt malaria conditions are somewhat different. There are areas as heavily infected as the interior, whilst other parts are slightly malarious. The principal inhabitants, the American Indians, give evidence of lack of tolerance to $P$. falciparum which also predominates here. $A$. darling $i$ is found in regions where malarial incidence is very high.

The coastal areas where the greater portion of the population lives are quite different. Malaria prevails here mainly in benign forms ( $P$. vivax and $P$. malariae infections) and its rate is also much lower. Besides, its geographical distribution is very patchy. There are some rural districts (Coronie and Nickerie) which are nearly free from malaria. But everywhere, except in the capital, Paramaribo, Anopheles aquasalis which is responsible for the transmission of coastal malaria, abounds. The only explication is that aquasalis may be composed of a complex of species of which only a portion is dangerous.

Literatur

C. Bonne, 1924. Malaria in Suriname. Nederl. Tijdschr. v. Geneesk. $68, I I$, p. 616-637.

C. Bonne \& J. Bonne-Wepster, 1925. Mosquitoes of Surinam. Meded. Kolon. Inst. 21, Afd. Trop. Hyg. 13.

P. C. FLU, 1912. Rapport over het wetenschappelijk onderzoek naar het voorkomen der malaria in de bovenlanden der kolonie Suriname en de bestudering van die ziekte. Algemeene Landsdrukkerij, 's-Gravenhage.

D. C. Geijskes, 1946. Notes on the neotropical Anophelinae in Moengo, Surinam. Mosquito News 6, p. 113-118.

E. VAN DER KUYP, 1949. Annotated list of mosquitoes of the Netherlands Antilles..... Docum. Neerl. Indon. morbis trop. I, p. 69-70.

E. VAN DER KUyP, 1949. Preliminary report on the subgenus Nyssorhynchus (Diptera, Culicidae) of Surinam (Dutch Guiana). Docum. Neerl. Indon. morbis trop. I, p. 67-68.

E. VAN DER KUYP, 1950. Contribution to the study of the malarial epidemiology in Surinam. Meded. Ind. Inst. 89, Afd. Trop. Hyg. 18.Tevens diss. Amsterdam.

N. H. Swellengrebel, in collaboration with E. VAN DER KuYP, 1940. Health of white settlers in Surinam. Spec. Publ. Colon. Inst. Amsterdam 54, Dep. Trop. Hyg. 16. 